\section{Obituary Wagner H Bridger}

Neuropsychopharmacology (2009) 34, 2786; doi: 10.1038/npp.2009.76

Dr Wagner H Bridger, former Professor and Chair of the Department of Psychiatry at the Medical College of Pennsylvania, died on February 10 after a long illness at the age of 81 years. His parents came from Eastern Europe and were of good non-religious Jewish stock. His father, unschooled but highly educated, had two sons. He named one of them Wagner after the great composer, the other Dante, after the Italian poet. This could not have been the easiest thing for the two boys in New York during and after the war. Wagner's social activism probably derived from his father and was clearly an important part of his life.

Wagner enrolled at NYU as an undergraduate and graduated as MD at the age of 22 years. He interned in Chicago, entered his residency at NYU, followed by a research fellowship at Hopkins. This resulted in his first publication with Horsley Gantt, the Dean of Pavlovian Psychology at that time. Later, he was associated with the Albert Einstein College of Medicine for 26 years before assuming the chairmanship of the Department of Psychiatry at the then Medical College of Pennsylvania, where I joined him in 1984. This was a fully accredited training program that had no lectures in psychopharmacology at that time.

In September of 1984, I gave one lecture on schizophrenia to cover its history, diagnosis, genetics, and treatment. There were three lectures on the psychodynamics of schizophrenia. Within a short duration of time, Wagner created a department that had a national reputation and the start of an international reputation with people such as Alan Bellack, Emil Coccarro, Edna Foa, Ira Katz, Doug Levenson, and me, all of whom received NIMH grants. All this changed dramatically when the mission of the medical school changed from an effort to produce science to an effort to produce money. Wagner was very good at getting people to come and work with him and do interesting things. However, he was neither very good nor very interested in making money. This sudden urge to make money, which appeared to hit many medical schools at this time, was reminiscent of what happened recently in Wall Street. All these changes were opposed by several Chairs, but only in private. The old covenanter hymn goes 'Dare to be a Daniel, dare to stand alone', and that was Wagner. He was the only Chair who opposed these unfortunate happenings. In the end, what had been a historical women's medical college that had changed its name to the Medical College of Pennsylvania disappeared.

He published conditioning studies from his initial days at Hopkins. These studies included neonates and children, with time out to publish a refutation of Jensen's position on 'Intelligence Race, Social Class and Heredity.' He published over 100 papers, was a founding member of the Society of Biological Psychiatry and President of the Society in 1988, and Editor of the journal from 1992 to 1997. He was active in many other organizations such as the Society of Research and Child Development, Planned Parenthood of New York, the Medical Committee for Human Rights, as well as the ACNP.

Those who knew Wagner will remember him most for his pleasant, provocative, puckish mode of questioning and arguing, and his ability to get to the heart of a problem very quickly. He had an enormous talent for getting on with people, despite his ability to stand up for what he believed in, and he will be remembered for his distinguished mentorship, love of science, life, family, martinis, and cigars. He is survived by his wife of 35 years, Rita Hayes Bridger, 7 children and 11 grand children.

George M Simpson ${ }^{1}$

${ }^{1}$ Department of Psychiatry and the Behavioral Sciences, LAC + USC School of Medicine, Psychiatric Outpatient Clinic IRD, Los Angeles, CA, USA 